BED VELOCITY (DM/A)

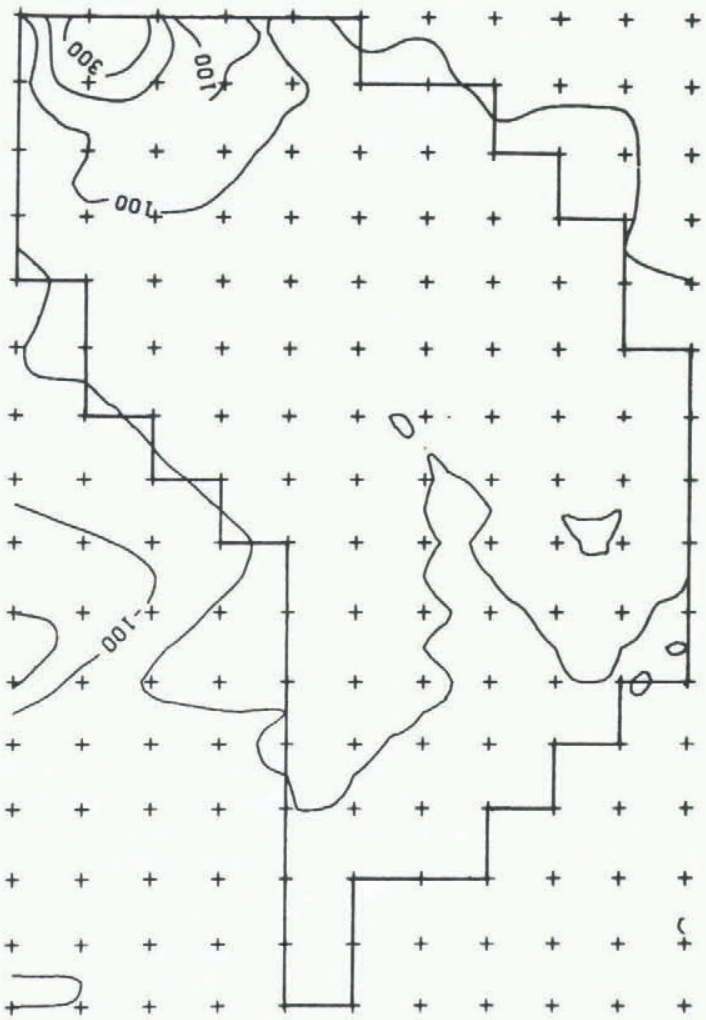

(e) Velocity of ice at the bottom of the ice.
BED TEMPERATURE (C)

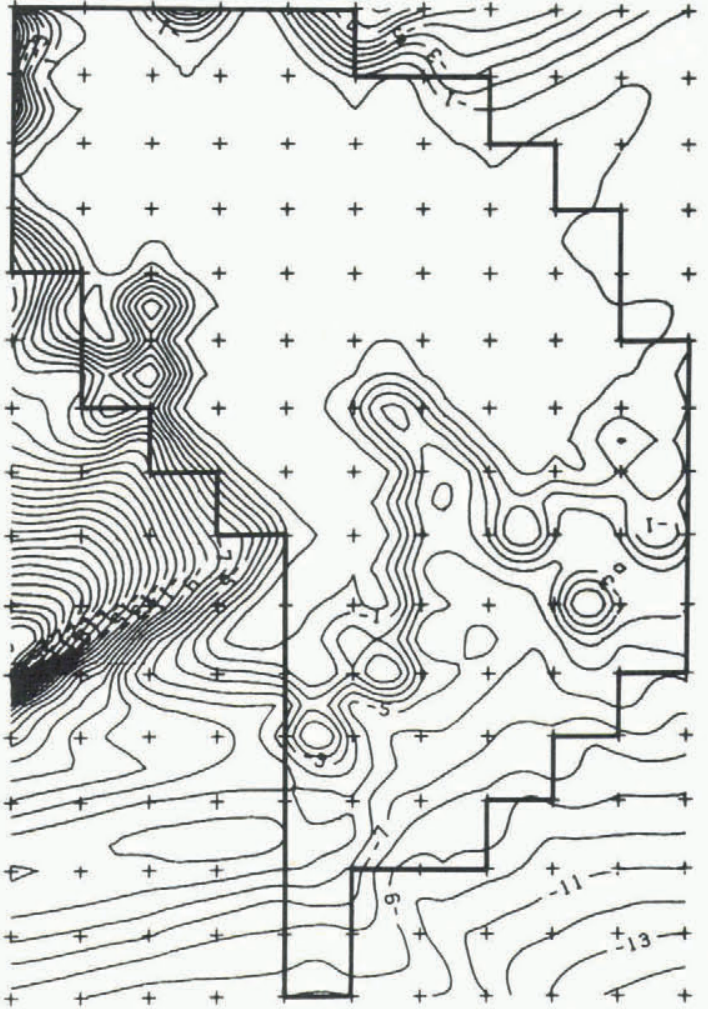

(f) Temperature at the bottom of the ice.

Fig.1. An example of the computer simulation. Details of calculations including initial and boundary conditions (input data) will be given elsewhere. Output results $40 \mathrm{ka}$ after glaciation started from homogeneous 1 000 m ice thickness are shown in $(c),(d),(e)$ and $(f)$.

\title{
A MODEL OF THE ANTARCTIC ICE SHEET INCLUDING
}

\section{THERMODYNAMICS}

\section{(Abstract)}

\author{
by
}

\section{J. Oerlemans}

(Instituut Meteorologie en Oceanografie, Rijksuniversiteit Utrecht, Princetonplein 5, Utrecht 2506, The Netherlands)

Much of the research work on the dynamics of large ice sheets has employed the "flowline approach" (e.g. Young 1981). However, present-day computer facilities now allow the use of two- and three-dimensional models as well. This opens up the possibility of simulating the transient behaviour of large ice sheets, including the effects of irregular bedrock topography, ice shelves, accumulation distribution, etc.

This presentation reports an attempt to construct a time-dependent, two-dimensional (i.e. vertically integrated) model of the entire Antarctic ice sheet. The basic model has been described in 0erlemans (1982). on a grid of $100 \mathrm{~km}$ spacing, it calculates horizontal ice-mass discharge using a constant flow parameter, bedrock adjustment, and the distribution of ice shelves. The evolution of the ice sheet is then obtained from the continuity equation. In this model the ice-accumulation rate depends on temperature, surface slope and distance to open water.
The model has recently been refined by including a calculation of the temperature field in the ice sheet and the associated feedback on the ice-mass discharge. This involves the dependence of internal deformation on ice temperature as well as increased sliding when basal water is present.

Results from this model version indicate that a large part of the West Antarctic ice sheet is always subject to basal melting, even if surface temperature drops by $5 \mathrm{~K}$. The East Antarctic ice sheet, on the other hand, shows a tendency to behave periodically, much in the same way as described in 0erlemans (1983). The period of oscillation is typically $10 \mathrm{ka}$ but depends strongly on such factors as iceaccumulation rate, sea-level temperature, and particularly on how the effect of basal water production on ice-mass discharge is parameterized.

Future work will concentrate on this last point, and also on how reduction of normal pressure by 
buoyancy effects (Budd and others 1979) modifies the evolution of the ice sheet. An attempt will then be made to simulate the Holocene retreat of the Antarctic ice sheet.

REFERENCES

Budd W F, Keage P L, Blundy N A 1979 Empirical studies of ice sliding. Jourmal of Glaciology 23(89): $157-170$
Oerlemans $\mathrm{J} 1982$ A model of the Antarctic ice sheet. Nature 297(5867): 550-553

Derlemans J 1983 A numerical study on cyclic behaviour of polar ice sheets. Tellus 35A: 81-87

Young N W 1981 Responses of ice sheets to environmental changes. Intemational Association of Hydrological Sciences Publication 131 (Symposium at Canberra 1979 - Sea Level, Ice and Climatic Change): $331-360$

\title{
SOUTHERN OCEAN SEA-ICE RESPONSE TO
}

\section{ATMOSPHERIC WARMING}

\author{
(Abstract) \\ by \\ Claire L. Parkinson and Robert A. Bindschadler \\ (Goddard Laboratory for Atmospheric Sciences, NASA/Goddard Space Flight Center, \\ Greenbelt, Maryland 20771, U.S.A.) \\ temperature change, the sensitivity of the position \\ of the ice edge decreasing as temperatures are fur- \\ ther increased. This nonlinearity in the response of \\ the ice edge occurs in the response of other ice \\ variables as well, including the total ice area and \\ total ice volume at maximum ice extent. These maxi- \\ mum areas and volumes decrease by roughly half with \\ an atmospheric temperature increase of $5 \mathrm{~K}$. Among the \\ other simulation results of increasing the atmos- \\ pheric temperatures is an increase in the temporal \\ asymmetry in the annual cycle of ice cover, showing \\ longer, slower periods of ice growth and shorter, \\ faster periods of ice decay. \\ The results of this study are described in full \\ in a paper to appear in: Hansen J, Takahashi T (eds) \\ Climate processes: sensitivity to solar irradiance \\ and $\mathrm{CO}_{2}$. Washington, DC, American Geophysical Union \\ (M Ewing Series 4).
}

The response of Antarctic sea ice to hypothetical atmospheric temperature increases has been simulated with a thermodynamic/dynamic sea-ice model having horizontal resolution of approximately $200 \mathrm{~km}$. The model was run, as a standard case, with mean-monthly climatological air temperatures and dew points, followed by four subsequent simulations with ail temperatures and dew points uniformly increased by $-1,+1,+3$, and $+5 \mathrm{~K}$. A temperature increase of $3 \mathrm{~K}$ suffices to el iminate the mid-summer ice around all of East Antarctica, with ice remaining only in the Amundsen and western Weddell seas. A temperature increase of $5 \mathrm{~K}$ suffices to el iminate the summer ice cover almost entirely, a small amount of ice remaining only off the Thwaites Glacier region in the Amundsen Sea. In winter, the hemispheric average of the calculated ice-edge retreat rates is $1.4^{\circ}$ latitude for each $1 \mathrm{~K}$ increase in atmospheric temperature. These retreat rates are nonlinear with respect to

\section{PAST ACCUMULATION RATES AT CAMP CENTURY AND}

\section{DEVON ISLAND, DEDUCED FROM ICE-CORE}

\section{MEASUREMENTS}

\section{(Abstract)}

by

\section{W. S. B. Paterson}

(Paterson Geophysics Inc., Box 303, Heriot Bay, British Columbia V0P 1H0, Canada)

\author{
and E. D. Waddington
}

(Geophysics Program AK50, University of Washington, Seattle, Washington 98195, U.S.A.)

Measurements of oxygen-isotope ratio in cores from polar ice sheets have provided detailed longterm records of past fluctuations in temperature. Cores in which annual layers can be identified also contain a record of past precipitation rates provided that one can calculate the total vertical strain to which each layer has been subjected since it was deposited at the surface. Because this is difficult, few such records have been published so far.
Nye (1963) proposed a method based on the assumption that the vertical strain-rate along any vertical line in the ice was uniform at any instant and that there was no basal melting. The first assumption is invalid and the method gives implausible results in the cases in which we have used it. Reeh and others (1978) obtained continuous records of precipitation, extending back to $600 \mathrm{AD}$ in one case, from three cores in Greenland. They also assumed that the vertical strain-rate did not vary with depth, but only 